\title{
Coexistence of Late-Onset Systemic Lupus Erythematosus With Focal Segmental Glomerulosclerosis and Lichen Planus: A Case Report
}

\author{
Betül SARGIN, Gülcan GÜRER \\ Department of Physical Medicine and Rehabilitation, Division of Rheumatology, \\ Medical Faculty of Adnan Menderes University, Aydin, Turkey
}

\begin{abstract}
Lichen planus and lupus nephritis with late-onset systemic lupus erythematosus (LO-SLE) may occur concomitantly. However, coexistence of LO-SLE with focal segmental glomerulosclerosis and lichen planus has not been defined. In this article, we report a 57-year-old male patient presenting with lichen planus and focal segmental glomerulosclerosis who was subsequently diagnosed with LO-SLE. To the best of our knowledge, this is the first case of LO-SLE presenting with lichen planus and focal segmental glomerulosclerosis.

Keywords: Focal segmental glomerulosclerosis, late-onset systemic lupus erythematosus, lichen planus.
\end{abstract}

Late-onset systemic lupus erythematosus (LO-SLE) is defined when SLE develops after the age of 50 years and occurs in 3 to $18 \%$ of SLE patients. This late onset age has a strong modifying effect on the clinical presentation, disease course, response to treatment, and prognosis of SLE. LO-SLE often has delayed diagnosis and less common occurrence of severe manifestations. Arnaud et al. ${ }^{1}$ suggests that pulmonary involvement and serositis are more frequent in LO-SLE, whereas malar rash, photosensitivity, arthritis, and nephropathy occur less commonly.

In this article, we report a male patient presenting with lichen planus (LP) and focal segmental glomerulosclerosis (FSGS) who was subsequently diagnosed with LO-SLE. Our literature scan did not reveal any report on FSGS and LP as an initial manifestation in LO-SLE.

\section{CASE REPORT}

A 57-year-old male patient presented with complaints of pain in both hands and skin lesions in the left ankle for the last one year (Figure 1). He described symmetric joint pain and morning stiffness for longer than one hour. He had a two-year history of arthralgia and of using topical steroid and nonsteroidal anti-inflammatory drugs. He did not have any history of cutaneous lesions, oral or nasal ulcers, alopecia, pleural effusion, neuropathy, psychosis, seizures or myelitis. He did not have previous laboratory analyses. He had no history of smoking or alcohol consumption, or hypertension. His general condition was moderate, oriented, and cooperated. His blood pressure was $160 / 80 \mathrm{mmHg}$, and heart rate and temperature were normal. Locomotor system 


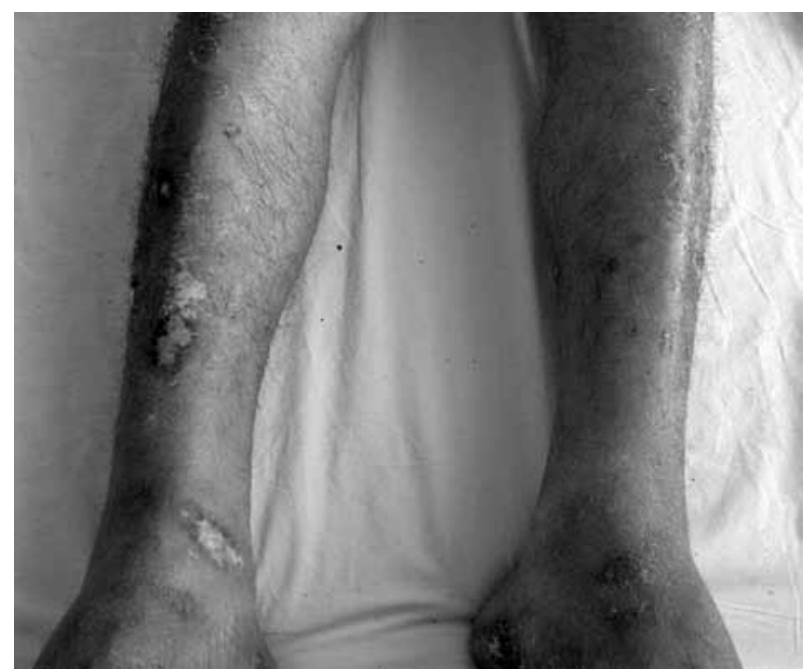

Figure 1. Violaceous pruritic papules with hyperkeratotic surface on the left ankle.

examination revealed tenderness and pain in both hands. Patient's laboratory findings are presented in Table 1. Blood tests revealed anemia with hemoglobin of $10.7 \mathrm{~g} / \mathrm{dL}$, hematocrit of $32.4 \%$, white cell count of $9.24 \mu \mathrm{l} / \mathrm{L}$, and platelet count of $291,000 \mu \mathrm{l} / \mathrm{L}$. Blood urea nitrogen and creatinine were $119 \mathrm{mg} / \mathrm{dL}$ and $1.48 \mathrm{mg} / \mathrm{dL}$, respectively. Urine analyze showed proteinuria of 5.68 grams/day and microalbuminuria of 1.24 grams/day. A skin biopsy was taken and the histology showed epidermal acanthosis, hyperparakeratosis with thickening of the granular cell layer, and an intense perivascular mononuclear cell infiltration at the superficial dermis. Direct immunofluorescence assay from the lesions showed immunoglobulin $\mathrm{M}$ and C3 deposits. According to characteristic histological changes, LP was diagnosed (Figure 1). Ultrasound-guided tru-cut renal biopsy of the left kidney was performed which revealed global sclerosis of four glomeruli and segmental sclerosis of one glomeruli. Furthermore; chronic inflammation, fibrosis, tubular atrophy, tiroidization, and focal medial thickening were also seen in interstitial area. No deposits were revealed in direct immunofluorescence assay. Finally, pathology was consistent with FSGS (Figure 2). Due to the presence of symmetric joint pain and morning stiffness for longer than one hour, acute-phase proteins including erythrocyte sedimentation rate and C-reactive protein, immunological tests including rheumatoid factor and anti-cyclic citrullinated peptide and antinuclear antibody were investigated. These tests showed positive antinuclear antibody (1: 1000 granular pattern), anti-Ro (SSA) antibody (2+), anti-La (SSB) antibody (3+), Ro-52 (3+), and direct Coombs test (immunoglobulin G) (4+). Anti-neutrophil cytoplasm antibody, rheumatoid factor, anti-cyclic citrullinated peptide, anticardiolipin immunoglobulin $\mathrm{M} / \mathrm{G}$, and venereal disease

Table 1. Laboratory findings of patient

\begin{tabular}{|c|c|c|}
\hline & Values & Normal range \\
\hline Hemoglobin (g/dL) & 10.7 & $11.7-15.5$ \\
\hline Hematocrit (\%) & 32.4 & $37-44$ \\
\hline Leukocyte count ( $\mu \mathrm{l} / \mathrm{L})$ & 9.24 & $3,800-11,000$ \\
\hline Platelet $(\mu \mathrm{l} / \mathrm{L})$ & 291,000 & $150,000-350,000$ \\
\hline Erythrocyte sedimentation rate $(\mathrm{mm} / \mathrm{h})$ & 9 & $0-20$ \\
\hline C-reactive protein $(\mathrm{mg} / \mathrm{L})$ & 0.72 & $0-6$ \\
\hline Urea $(\mathrm{g} / \mathrm{dL})$ & 119 & $13-43$ \\
\hline Creatinine (mg/dL) & 1.48 & $0.7-1.3$ \\
\hline Rheumatoid factor (IU/mL) & 14.0 & $0-18$ \\
\hline Anti-cyclic citrullinated peptide (unit/mL) & 0.6 & $0-2.5$ \\
\hline Antinuclear antibody & 1: 1000 granular pattern & Negative \\
\hline Anti-Ro antibody & ++Positive & Negative \\
\hline Anti-La antibody & +++Positive & Negative \\
\hline Ro-52 (52 Kda) & +++Positive & Negative \\
\hline Anti-neutrophil cytoplasm antibody & Negative & Negative \\
\hline Anticardiolipin IgM/IgG & Negative & Negative \\
\hline Venereal disease research-RPR test & Negative & Negative \\
\hline $\mathrm{C} 4(\mathrm{mg} / \mathrm{dL})$ & 22.9 & $15-50$ \\
\hline Double-stranded DNA (dsDNA) antibody & Negative & Negative \\
\hline Direct coombs test (IgG) & ++++ Positive & Negative \\
\hline
\end{tabular}




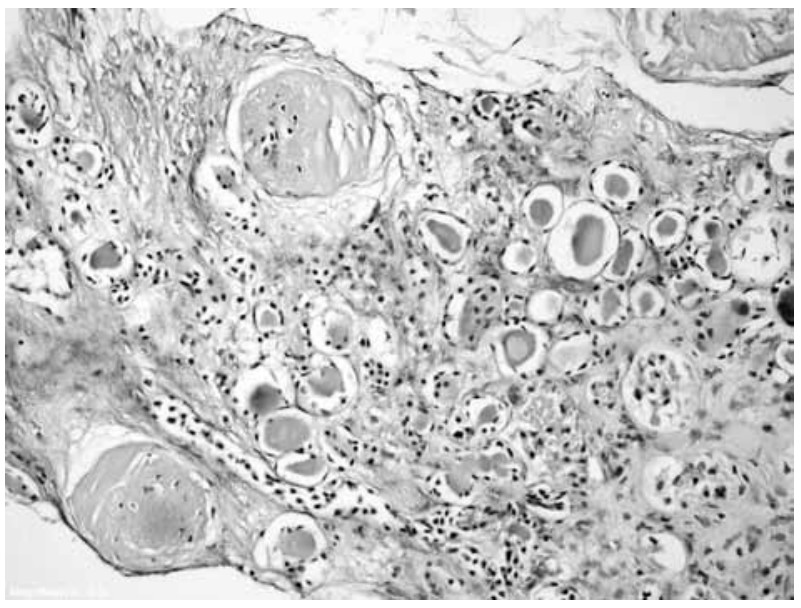

Figure 2. Histologic findings in the patient's kidney biopsy. Periodic acid-Schiff (PAS) staining (200× magnification) shows segmental glomerulosclerosis and interstitial fibrosis with multiple foci of microcystic tubular dilation.

research-rapid plasma reagin tests were negative while complement levels were normal. Doublestranded deoxyribonucleic acid antibody was negative. He fulfilled the Collaborating Clinics criteria for SLE. ${ }^{2}$ The patient was diagnosed as LO-SLE and administered methylprednisolone (1 $\mathrm{mg} / \mathrm{kg}$ body weight), mycophenolate mofetil $(1,000 \mathrm{mg})$, perindopril $(5 \mathrm{mg})$, and acetylsalicylic acid $(100 \mathrm{mg})$ treatment. We started perindopril as an angiotensin converting enzyme inhibitor. Methylprednisolone (16 mg) treatment was administered for LP. After this treatment, patient's microalbuminuria and proteinuria levels regressed to $24.0 \mathrm{mg} / 24$ hours and $150.0 \mathrm{mg} / 24$ hours, respectively. His joint complaints improved and edema of the lower extremities decreased. His blood pressure was $120 / 80 \mathrm{mmHg}$ during the follow-up period and other vital signs were normal. Blood urea nitrogen and creatinine levels regressed to $58 \mathrm{mg} / \mathrm{dL}$ and $1.2 \mathrm{mg} / \mathrm{dL}$, respectively. He was discharged from our clinic with healing, and was proposed a control examination for two weeks later. A written informed consent was obtained from the patient.

\section{DISCUSSION}

To the best of our knowledge, this is the first case of LO-SLE presenting with LP and FSGS. Age at onset of SLE influences the clinical expression of the disease, thus LO-SLE has a different profile, compared with younger patients. ${ }^{3}$ Studies have reported that LO-SLE patients have less prevalent typical manifestations like rash or renal involvement. Sicca syndrome ${ }^{4}$ pericarditis, and lung involvement are more common as initial manifestations of LO-SLE. Choi et al. ${ }^{5}$ reported that decreased complement levels are more common in juvenile SLE. Webb et al. ${ }^{6}$ reported that doublestranded deoxyribonucleic acid antibody results can be heterogeneous. Skin involvement is seen in about 70 to $85 \%$ of all lupus erythematosus (LE) cases. ${ }^{7}$ Cutaneous features of LE can be classified into LE-specific and LE-nonspecific skin lesions. LE-specific skin lesions are very heterogeneous. LE-specific cutaneous involvement includes acute cutaneous LE with its localized and generalized forms, subacute cutaneous LE with its annular and papulosquamous forms, and chronic cutaneous LE including discoid LE, lupus panniculitis, and chilblain lupus. ${ }^{8}$ LE-nonspecific skin lesions are morphologically varied and include vasculitis, livedo reticularis, photosensitivity, alopecia, Raynaud's phenomenon, and bullous lesions. ${ }^{9}$ The prevalence of LP in LE is not known since this condition is very rare. In the literature, coexistence of LP and SLE were presented as case reports. Thormann ${ }^{10}$ reported the first case of ulcerative LP of the feet in a patient with SLE. After this report, Ahmed et al. ${ }^{11}$ demonstrated three cases of simultaneous occurrence of LP and SLE. $\mathrm{Ng}$ et al. ${ }^{12}$ reported pemphigus foliaceus and oral LP in a patient with SLE and thymoma. Kobayashi et al. ${ }^{13}$ reported a SLE case with LP-like eruptions and pericarditis. Koga et al. ${ }^{14}$ presented a 71-year-old Japanese female as a case of LO-SLE with LP-like eruption and cardiac tamponade, while our LO-SLE case presented with LP and renal involvement. In a study conducted by Kobkitcharoen et al., ${ }^{15} 30$ lupus nephritis patients (7 males and 23 females) with a disease onset beyond the age of 50 years were enrolled between 1989 and 2006. Renal biopsy was performed on all patients and histological classifications were categorized according to 2003 International Society of Nephrology/Renal Pathology Society classification. The most common renal histologic finding of lupus nephritis was diffuse proliferative glomerulonephritis (63.30\%). Authors indicated that FSGS was uncommon. Furthermore, Adu et al. $^{16}$ found FSGS in two patients among 
17 LO-SLE patients. After this study, Papo et al. ${ }^{17}$ indicated idiopathic FSGS in a patient with SLE as an unusual combination. Baranowska-Daca et al. ${ }^{18}$ noticed a 41-year-old SLE patient with FSGS and membranous glomerulonephritis. Another case of FSGS has been recently described in a transplant kidney of a patient with SLE who presented with nephrotic proteinuria on postoperative day four, a behavior observed in recurrent FSGS. FSGS was preceded three to 18 years by renal abnormalities, which were related mostly to a previous lupus glomerulonephritis. ${ }^{19}$ How nonlupus nephritis develops in patients with SLE and FSGS is poorly understood according to Tariq et al.'s case report. ${ }^{20}$ They suggested that it may be pathogenetically related to SLE. To our knowledge, our patient is the first case of LO-SLE presenting with LP and FSGS. We may conclude that LP and FSGS may be one of the unusual variations of LO-SLE and elderly patients with LP-like eruptions and proteinuria should be carefully followed-up until a final diagnosis can be established.

\section{Declaration of conflicting interests}

The authors declared no conflicts of interest with respect to the authorship and/or publication of this article.

\section{Funding}

The authors received no financial support for the research and/or authorship of this article.

\section{REFERENCES}

1. Arnaud L, Mathian A, Boddaert J, Amoura Z. Late-onset systemic lupus erythematosus: epidemiology, diagnosis and treatment. Drugs Aging 2012;29:181-9.

2. Tiao J, Feng R, Carr K, Okawa J, Werth VP. Using the American College of Rheumatology (ACR) and Systemic Lupus International Collaborating Clinics (SLICC) criteria to determine the diagnosis of systemic lupus erythematosus (SLE) in patients with subacute cutaneous lupus erythematosus (SCLE). J Am Acad Dermatol 2016;74:862-9.

3. Rovensky J, Tuchynová A. Systemic lupus erythematosus in the elderly. Autoimmun Rev 2008;7:235-9.

4. Stefanidou S, Gerodimos C, Benos A, Galanopoulou V, Chatziyannis I, Kanakoudi F, et al. Clinical expression and course in patients with late onset systemic lupus erythematosus. Hippokratia 2013;17:153-6.

5. Choi JH, Park DJ, Kang JH, Yim YR, Lee KE, Lee JW, et al. Comparison of clinical and serological differences among juvenile-, adult-, and late-onset systemic lupus erythematosus in Korean patients. Lupus. 2015;24:1342-9.

6. Webb R, Kelly JA, Somers EC, Hughes T, Kaufman KM, Sanchez E, et al. Early disease onset is predicted by a higher genetic risk for lupus and is associated with a more severe phenotype in lupus patients. Ann Rheum Dis 2011;70:151-6.

7. Vera-Recabarren MA, García-Carrasco M, Ramos-Casals M, Herrero C. Cutaneous lupus erythematosus: clinical and immunological study of 308 patients stratified by gender.Clin Exp Dermatol 2010;35:729-35.

8. Szczech J, Rutka M, Samotij D, Zalewska A, Reich A. Clinical characteristics of cutaneous lupus erythematosus. Postepy Dermatol Alergol 2016;33:13-7.

9. Stannard JN, Kahlenberg JM. Cutaneous lupus erythematosus: updates on pathogenesis and associations with systemic lupus. Curr Opin Rheumatol 2016;28:453-9.

10. Thormann J. Ulcerative lichen planus of the feet. A case in which the serological findings suggested systemic lupus erythematosus. Arch Dermatol 1974;110:753-5.

11. Ahmed AR, Schreiber P, Abramovits W, Ostreicher M, Lowe NJ. Coexistence of lichen planus and systemic lupus erythematosus. J Am Acad Dermatol 1982;7:478-83.

12. Ng PP, Ng SK, Chng HH. Pemphigus foliaceus and oral lichen planus in a patient with systemic lupus erythematosus and thymoma. Clin Exp Dermatol 1998;23:181-4.

13. Kobayashi T, Hatamochi A, Kamada N, Matsue H, Shinkai H. Systemic lupus erythematosus with lichen planus-like eruptions associated with pericarditis. J Dermatol 2008;35:306-7.

14. Koga T, Kubota Y, Kiryu H, Nakayama J, Takeda S, Kono K. Late onset systemic lupus erythematosus with lichen planus-like eruption and cardiac tamponade. Eur J Dermatol 2000;10:620-2.

15. Kobkitcharoen M, Teerapornlertratt T, Chawanasuntorapoj R, Chanchairujira T, Laowahutanont N, Parichatikanond P, et al. Late onset lupus nephritis: analysis of clinical manifestations and renal pathological features in Siriraj Hospital. J Med Assoc Thai 2012;95:213-7.

16. Adu D, Williams DG, Taube D, Vilches AR, Turner DR, Cameron JS, et al. Late onset systemic lupus erythematosus and lupus-like disease in patients with apparent idiopathic glomerulonephritis. Q J Med 1983;52:471-87.

17. Papo T, Faucher C, Huong DL, Beaufils $\mathrm{H}$, Piette JC, Godeau P. Idiopathic focal segmental glomerulosclerosis in a patient with systemic lupus erythematosus: an unusual combination. Am J Kidney Dis 1994;24:880-1.

18. Baranowska-Daca E, Choi YJ, Sheth A, Cartwight J Jr, Truong LD. Nephrotic syndrome 
associated with focal segmental glomerulosclerosis in a patient with systemic lupus erythematosus and membranous glomerulonephritis in remission. Am J Kidney Dis 1999;34:22.

19. Kim JS, Sugar L, Zaltzman JS. Development of focal segmental glomerulosclerosis in the renal allograft of a patient with lupus. Am J Kidney Dis 1999;34:13.

20. Tariq H, Rafiq A, Franchin G. Collapsing focal segmental glomerulosclerosis in a patient with systemic lupus erythematosus. Case Rep Med 2014;2014:732192. 